\title{
Kernos
}

Revue internationale et pluridisciplinaire de religion grecque antique

$28 \mid 2015$

Varia

\section{Perception et construction du divin dans}

l'Antiquité

André Motte

\section{OpenEdition}

Journals

Édition électronique

URL : http://journals.openedition.org/kernos/2353

DOI : 10.4000/kernos.2353

ISSN : 2034-7871

\section{Éditeur}

Centre international d'étude de la religion grecque antique

\section{Édition imprimée}

Date de publication : 1 octobre 2015

Pagination : 285

ISBN : 978-2-87562-055-2

ISSN : 0776-3824

Référence électronique

André Motte, "Perception et construction du divin dans l'Antiquité », Kernos [En ligne], 28 | 2015, mis en ligne le 01 octobre 2015, consulté le 24 septembre 2020. URL : http://journals.openedition.org/ kernos/2353 ; DOI : https://doi.org/10.4000/kernos.2353

Ce document a été généré automatiquement le 24 septembre 2020 


\title{
Perception et construction du divin dans l'Antiquité
}

\author{
André Motte
}

\section{RÉFÉRENCE}

BORGEAUD Philippe, FABIANO Doralice (éd.), Perception et construction du divin dans

l'Antiquité, Genève, Droz, 2013. 1 vol. $15 \times 22 \mathrm{~cm}, 358$ p. (Recherches et Rencontres, 31).

ISBN : 978-2-600-01644-5.

Ce livre publie les Actes du colloque qui s'est tenu à Genève, en mars 2011, sous l'intitulé «Perception des dieux, émotions, maîtrise rituelle: corps divins, corps humains", dans le cadre des rencontres organisées par les responsables des programmes de recherche FIGVRA. Représentation du divin dans les sociétés grecque et romaine (Groupe européen) et Myth and Rite as a cultural Expression of Emotions (Genève). Dans leur remarquable présentation, les deux éditeurs distinguent trois pôles que parcourt le thème traité. Il $\mathrm{y}$ a tout d'abord la représentation du corps des dieux sous la forme de statues et la perception qu'on s'en fait dans le contact rituel, mais aussi l'appréhension de cette corporéité dans l'espace sacré, lequel peut être perçu comme l'artisan et le témoin des épiphanies divines. Le deuxième pôle concerne les altérations que manifeste le corps humain au contact du divin et que le rituel contribue à maitriser. Le troisième pôle, qui constitue comme un trait d'union entre la représentation des dieux et leur perception, s'attache à élucider les liens complexes qui relient celles-ci et dont les émotions sont un facteur décisif, car « elles sont à la fois indice sûr d'une présence, et matière à partir de laquelle mettre en scène cette présence ».

2 Cette présentation met le lecteur en grand appétit en ce qu'elle souligne bien l'originalité de l'approche et la riche densité donnée à l'étude de l'expérience religieuse, notamment par l'importance reconnue aux émotions. L'introduction se poursuit par un bref aperçu de l'apport de chacune des douze contributions; on en 
trouvera les noms d'auteurs et les titres ci-dessous (p. 299). L'Antiquité est représentée par deux études relevant du domaine romain, une étude relevant du domaine mésopotamien, une étude qui couvre à la fois les domaines phénicien, grec, romain et punique, les huit autres études ayant trait exclusivement au domaine grec. Ces contributions sont réparties en trois groupes: "Les dieux et leurs statues", "Les scènes d'une épiphanie » et «La politique des émotions ». Sans entrer dans le détail de chaque contribution, un apport global de l'ouvrage est de souligner les modalités variées de la " présentification » de l'invisible et de la mise en forme du contact qui se noue entre les sphères humaine et supra-humaine, que ce soit par l'intermédiaire d'un élément matériel (statue, sanctuaire, images) ou dans la corporéité même de celui qui « perçoit » ou « reçoit » la présence divine.

3 Très soignée, l'édition offre in fine un résumé de chaque article (en français et en anglais), trois index (noms propres, notions fondamentales, sources anciennes) ainsi qu'une table des illustrations, en noir et blanc (de bonne qualité), sauf sur la page de couverture qui donne à voir, en couleurs, un très beau vase du Metropolitan Museum de New York. M'est avis que cette publication marque un jalon important dans la réflexion sur la représentation complexe du divin dans l'Antiquité.

\section{AUTEURS}

\section{ANDRÉ MOTTE}

Université de Liège 